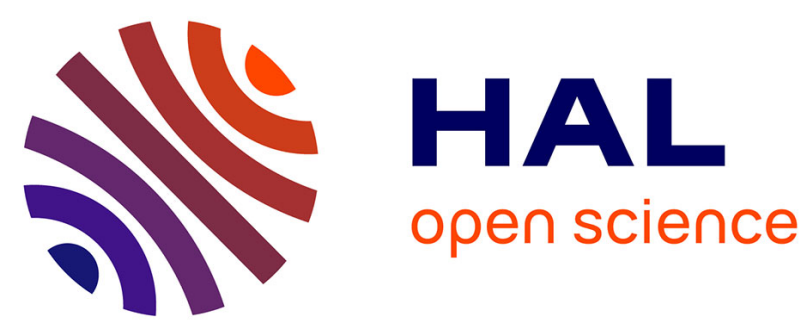

\title{
Correlations between effective permeability and marrow contact channels surface of vertebral endplates
}

\author{
Jean-Michel Laffosse, Franck Accadbled, François Molinier, Nicolas \\ Bonnevialle, Jérôme Sales de Gauzy, Pascal Swider
}

\section{- To cite this version:}

Jean-Michel Laffosse, Franck Accadbled, François Molinier, Nicolas Bonnevialle, Jérôme Sales de Gauzy, et al.. Correlations between effective permeability and marrow contact channels surface of vertebral endplates. Journal of Orthopaedic Research, 2010, 28 (9), pp.1229-1234. 10.1002/jor.21137 . hal-01591232

\section{HAL Id: hal-01591232 \\ https://hal.science/hal-01591232}

Submitted on 25 Sep 2017

HAL is a multi-disciplinary open access archive for the deposit and dissemination of scientific research documents, whether they are published or not. The documents may come from teaching and research institutions in France or abroad, or from public or private research centers.
L'archive ouverte pluridisciplinaire HAL, est destinée au dépôt et à la diffusion de documents scientifiques de niveau recherche, publiés ou non, émanant des établissements d'enseignement et de recherche français ou étrangers, des laboratoires publics ou privés. 


\section{Open Archive TOULOUSE Archive Ouverte (OATAO)}

OATAO is an open access repository that collects the work of Toulouse researchers and makes it freely available over the web where possible.

This is an author-deposited version published in : http://oatao.univ-toulouse.fr/ Eprints ID : 18182

To link to this article : DOI:10.1002/jor.21137

URL : $\underline{\text { http://dx.doi.org/10.1002/jor.21137 }}$

To cite this version : Laffosse, Jean-Michel and Accadbled, Franck and Molinier, François and Bonnevialle, Nicolas and Sales de Gauzy, Jérôme and Swider, Pascal Correlations between effective permeability and marrow contact channels surface of vertebral endplates. (2010) Journal of Orthopaedic Research, vol. 28 ( $\left.\mathrm{n}^{\circ} 9\right)$ ). pp. 1229-1234. ISSN 0736-0266

Any correspondence concerning this service should be sent to the repository administrator: staff-oatao@listes-diff.inp-toulouse.fr 


\title{
Correlations between Effective Permeability and Marrow Contact Channels Surface of Vertebral Endplates
}

\author{
Jean-Michel Laffosse, ${ }^{1,2}$ Franck Accadbled, ${ }^{2,3}$ François Molinier, ${ }^{1,4}$ Nicolas Bonnevialle, ${ }^{2,5}$ Jérôme Sales de Gauzy, ${ }^{2,3}$ \\ Pascal Swider 6 \\ ${ }^{1}$ Service de Chirurgie Orthopédique et Traumatologique, Institut Locomoteur, Centre Hospitalier Universitaire de Toulouse-Rangueil, 1 Avenue Jean \\ Poulhès, TSA 50032, 31059 Toulouse Cedex 9, France, ${ }^{2}$ Laboratoire de Biomécanique, CHU Toulouse, Toulouse, France, ${ }^{3}$ Service d'Orthopédique \\ Pédiatrique, Hôpital des Enfants, CHU Toulouse, Toulouse, France, ${ }^{4}$ Laboratoire d'Anatomie, CHU Toulouse, Toulouse, France, ${ }^{5}$ Service de \\ Chirurgie Orthopédique, CHU Toulouse-Pupan, France, ${ }^{6}$ IMFT UMR CNRS 5502, Toulouse, France
}

\begin{abstract}
Homeostasis of the intervertebral disc relies on nutrient supply and waste clearance through the dense capillary network that is in contact with the cartilage endplate (CEP). We developed a micro-computerized tomography (micro-CT) method to quantify the marrow contact channel surface (MCCS) with the CEP and to validate the hypothesis according to which MCCS was correlated to the effective permeability of the vertebral endplate (VEP) and influenced by the mechanical stimuli. The influence of compression loading on local vascularization was investigated. Six 4-week-old skeletally immature pigs were instrumented with left pedicle screws and rod at both T5-T6 and L1-L2 levels to create asymmetrical spine tethers. After 3 months of growth, three cylindrical specimens of the VEP (one central and two lateral right and left) were obtained from both the instrumented and the control levels. We used a previously validated method for measuring permeability. Micro-CT analysis (resolution $12 \mu \mathrm{m}$ ) yielded a gray-scale 2D-image of the discal end of each specimen converted into a binary 2D-image to derive the MCCS. Correlations between MCCS and effective permeability were assessed. Effective permeability and MCCS were significantly decreased compared to the control group especially on the tethered side $(-41.5 \%, p=0.004$ and $-52.5 \%, p=0.0009$, respectively). Correlations were significant and showed maximal value $\left(r^{2}=0.430, p<0.0001\right)$ on the tethered side involving maximal compressive loadings. Mechanical stimuli, due to unbalanced growth, altered the vascularization and the convective properties of the CEP. The cascade of mechanobiological events should offer perspectives for research on disc degeneration and attempted treatment.
\end{abstract}

Keywords: vertebral endplate; permeability; vascular network; spine; micro-CT scan

Solutes are transported to and from the intervertebral disc (IVD) by passive diffusion and mostly by an active convection mechanism. The latter mainly takes place through the cartilage endplate (CEP) of the vertebral endplate (VEP). ${ }^{1}$ Nutrients' transport is facilitated by the presence of a complex vascular network. ${ }^{2,3}$ Vascular buds are in direct contact with the CEP through marrow contact channels crossing the calcified layer of the VEP 4,5 which represents a barrier to solute transport. ${ }^{4,6}$ There is a link between permeability and vascular supply as permeability is greater in the center of the VEP ${ }^{6-8}$ where vascular network is the more dense. ${ }^{3,4,6}$ Oki et al. ${ }^{9}$ have shown that the density of the vascular buds does not vary significantly between the region of the CEP facing the annulus and the one facing the nucleus pulposus. However, they demonstrated some morphologic differences: vascular buds in the annulus region form simple loops whereas those facing the nucleus pulposus are organized in complex multiple loop networks. This latter morphology allows a greater capillary contact surface in the center of the VEP than in the periphery thus facilitating solutes transport in the center. Benneker et al. $^{5}$ demonstrated the indirect correlation between marrow contact channel occlusion, as analyzed on scanning electron microscopy images and IVD degeneration. Gruber et al. $^{2}$ evaluated on a semiquantitative scale, the VEP smoothness and porosity in a sand rat model using a $44-\mu \mathrm{m}$ resolution microcomputerized tomography (micro-CT) method. They noted changes in the vascular network with aging. However, no previous study has, to our knowledge, quantitatively scored the surface of the marrow contact channels of the VEP in contact with the CEP nor has correlated the vascular supply with the permeability of the VEP. ${ }^{10}$ In addition, while chemical factors have demonstrated their capacity to stimulate or to alter vascular supply to the CEP, ${ }^{11-13}$ mechanical factors could also be involved. ${ }^{14}$ As yet, no study has specifically addressed the role of a mechanical stimulus on the epiphyseal vascular supply in contact with the CEP.

The central hypothesis of our study was first, that marrow contact channels surface (MCCS) was correlated to effective permeability of the VEP and second that MCCS was influenced by pathological mechanical stimuli. To proceed, we implemented an experimental study in a growing porcine animal model subjected to an asymmetric vertebral tether in an intervertebral unit (vertebra-disc-vertebra).

\section{MATERIALS AND METHODS}

Surgical Procedure and Specimen Preparation ${ }^{15}$

All experiments were carried out in accordance with current regulations on the care and use of laboratory animals. Six 4week-old skeletally immature domestic pigs were instrumented with two left pedicle screws connected together in situ via a titanium rod at T5/T6 and L1/L2 levels ( titanium screws, Medtronic ${ }^{\mathbb{R}}$, Minneapolis, MN). The animals were operated on under general anesthesia and sterile surgical conditions and were given pre- and postoperative prophylactic antibiotics (cefazolin). A subcutaneous injection of low molecular weight heparin (enoxaparin, Lovenox ${ }^{\circledR} 4000$ IU, Sanofi Aventis, Lyon, France) was administered the day before and 

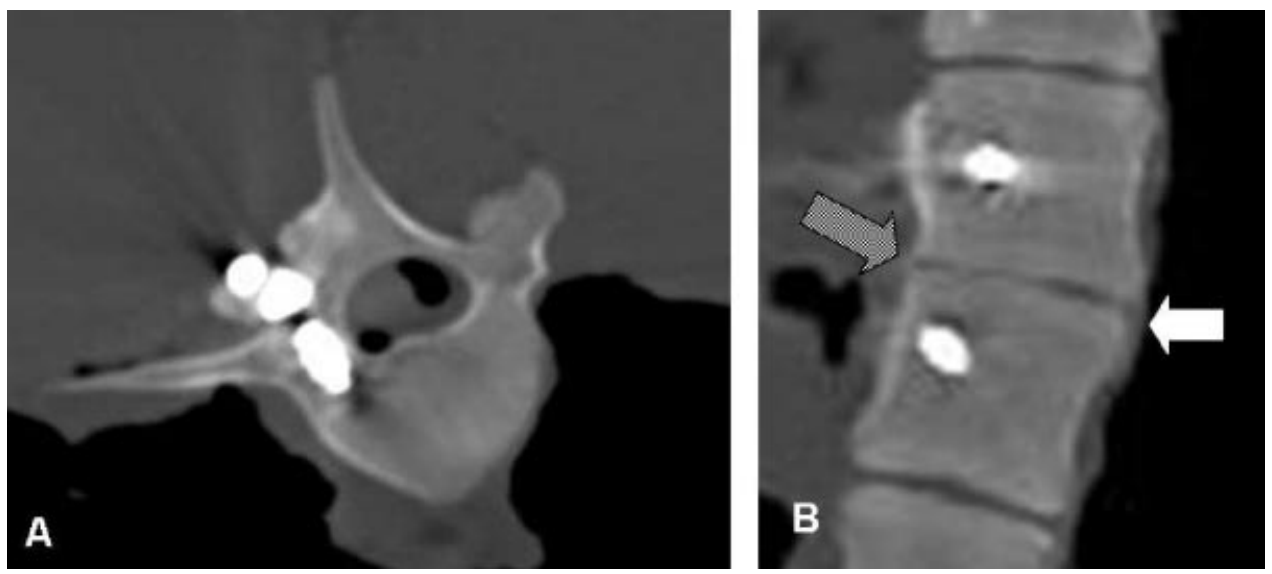

Figure 1. CT scan showing correct positioning of the pedicle screw both on the axial view (A) and the frontal $2 \mathrm{D}$ reconstructions (B). After 3 months of growth, spine tether resulted in asymmetric compression of the left side of the disc (black arrow) compared to the right side (white arrow)

the day of the procedure. No local or general complication was observed.

After 3 months, thoracolumbar spines were removed en bloc and immediately immersed into $6{ }^{\circ} \mathrm{C}$ isotonic saline solution. CT-scan was carried out to confirm correct positioning of the screws and disc wedging (Fig. 1). Instrumented thoracic (T5-T6) and lumbar (L1-L2) intervertebral units were isolated as well as those intervertebral units located two levels above the thoracic tether and two levels below the lumbar tether which were used as control, respectively. The IVD was removed from each plate using a beaver blade under binocular microscope to avoid any damage to the VEP and three cylindrical plugs (diameter $5 \mathrm{~mm}$, height $6 \mathrm{~mm}$ ) were harvested by means of a cylindrical punch. One specimen was taken from the central zone of the VEP and two were taken laterally: one left on the tethered side and one right on the nontethered side. Each specimen showed a stacking sequence of four layers: CEP, subchondral bone, growth plate, and adjacent trabecular bone. The edge of the specimen was at least $1.5 \mathrm{~mm}$ away from a screw. The specimens were carefully inserted into silicone tubes and then frozen for storage within $6 \mathrm{~h}$ at $-23^{\circ} \mathrm{C}$ in Ringer's solution added with $10 \%$ cryoprotectant dimethyl sulfoxide (DMSO) and $100 \mathrm{IU} / \mathrm{ml}$ heparin. ${ }^{8}$ Fracture of some specimens occurred during sampling and made them unsuitable either for permeability measurement or the micro-CT study. The number of available specimens for the entire study is reported in Table 1.

Table 1. Number of Available Specimens for the Study According to the Location of the Samples

\begin{tabular}{lcc}
\hline & Thoracic & Lumbar \\
\hline Control & 9 & \\
$\quad$ Left lateral & 7 & 12 \\
Central & 8 & 9 \\
$\quad$ Right lateral & & \\
Instrumented & 11 & 9 \\
$\quad$ Left lateral (tethered side) & 10 & 10 \\
$\quad$ Central & 12 & 11 \\
$\quad$ Right lateral (nontethered side) & & \\
\hline
\end{tabular}

Effective Permeability

A previously validated method for measuring permeability, based on the relaxation pressure due to a transient flow rate was used. ${ }^{10}$ Specimens were placed in the testing apparatus and a computer controlled pistoning device generated a fluid flow that fully saturated the cylindrical specimen with a maximal pressure of $0.1-0.2 \mathrm{MPa}$. The decrease of upstream pressure $P(t)$ was measured using a pressure transducer $\left(\mathrm{TME}^{\mathbb{R}}, 0-5\right.$ bars) and Labview ${ }^{\circledR}$ software (National Instrument, Austin, TX), which allowed the macroscopic permeability $\kappa_{0} / \mu$ of the specimens to be derived using Equation 1 . Parameters $P_{0}, \mu, \beta$, respectively, were the initial pressure, fluid viscosity, and the coefficient of the fixture previously calibrated.

$$
P(t)=P_{0} \mathrm{e}^{(-\kappa t) / \mu \beta}
$$

Three measurements were done for each specimen and in both flow directions, flow in (from the vertebral body towards the disc) and flow out (from the disc towards the vertebral body).

\section{Marrow Contact Channel Surface (MCCS) of the Vascular Buds} A micro-CT device ( $\mu$ CT40, Scanco Medical, Bassersdorf, Switzerland) was used. X-ray power was $70 \mathrm{kVp}$ and $88 \mu \mathrm{A}$. Each specimen was placed in a cylindrical sample holder in Ringer solution to prevent any motion or damage from drying during the scanning process. They were scanned continuously using jointed $12 \mu \mathrm{m}$ thick slices with an exposure time of $1,000 \mathrm{~ms}$ and an integration time of $100 \mathrm{~ms}$. Image matrix was $1,024 \times 1,024$ pixels and the voxel size was $12 \times 12 \times 12 \mu \mathrm{m}^{3}$. A reconstruction of the bitmap data set (raw data) was obtained and used to build a 3D model of each specimen (Fig. 2A). The $3 \mathrm{D}$ model images obtained with micro-CT were rotated in the $(x, y, z)$ reference frame to obtain a vertical view of the upper extremity of the specimen corresponding to the IVD/CEP interface.

Resulting 2D image in gray-scale mode (TIFF format) were used to investigate the geometrical surface properties (Fig. 2B and C). As shown previously, the capillary buds were in contact with the CEP through the marrow contact channels located into the subchondral bone. Micro-CT modality allowed calcified tissues to be reconstructed. The emergence of marrow contact channels into the surface of the specimen were seen as a distribution pattern of openings varying in density, size, and 

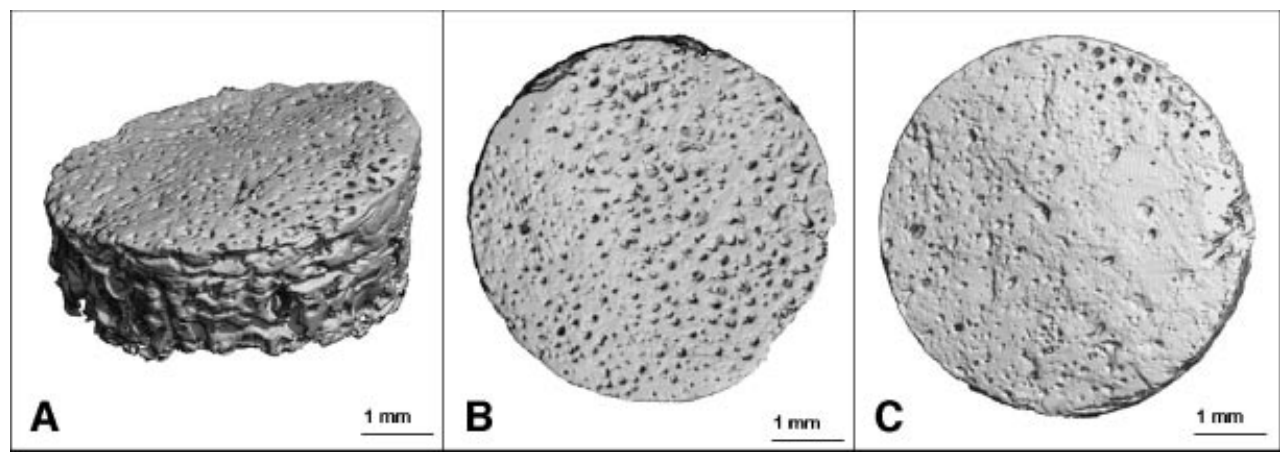

Figure 2. 3D reconstruction of a specimen using the bitmap data set (raw data) (A). Flat 2D image in gray-scale mode of the discal surface of the VEP (B) and (C), showing impressions made by the contact zones of the capillary network with the VEP. The capillary network is more dense in the center (B) than in the periphery (C).

shape as shown in Figure 2B and C. A script was designed to perform all specimen reconstructions with the same protocol and density parameters (Adobe Photoshop 5.5, Adobe Systems ${ }^{\circledR}$, Chicago, IL, UK). Using a fixed intensity level limit (50\% threshold), a binary image was created where the marrow contact channel appeared in black and the other material appeared in white (Fig. 3A and B). As some irregularities of the VEP were initially identified as vascular buds, we carried out a manual correction after comparison with the original images according to Benneker et al. ${ }^{5}$ Only the circular central area of each specimen (cross-section with diameter of $4.0 \mathrm{~mm}$ ) was examined to limit the artifacts on the margins of the specimen due to the specimen harvesting process. Because of significant variations of capillary contacts size and confluence of close buds, channels were not counted individually but their overall surface was quantified using dedicated image processing routines (Matlab ${ }^{\circledR}$, Mathworks, Natick, MA). Finally, a MCCS rate was then calculated for each specimen defined by the ratio of overall channel surface by the specimen cross-section considered.

\section{Statistical Analysis}

Data are presented as means \pm standard deviation. Analysis of intra- and interobserver reproducibility of MCCS from microCT measurements was carried out by calculating the intraclass correlation coefficient (ICC). The normality of distributions was verified using the Kolmogorov-Smirnov test and Levene test was used to determine the equality of variances. Student's $t$-tests were used to compare normally distributed variables (MCCS). For effective permeability, normality was not confirmed and we used nonparametric statistical methods: Wilcoxon rank test. Statistical significance was defined as $p<0.05$. Correlations between effective permeability and
MCCS were sought using Pearson or Spearman correlation coefficients $\left(r^{2}\right)$. Statistical analysis was carried out with SPSS 14.0 (SPSS, Inc., Chicago, IL).

\section{RESULTS}

Intra- and interobserver reproducibility were respectively $\mathrm{ICC}=0.95(95 \%$ CI $0.91-0.99)$ and $\mathrm{ICC}=0.89$ (95\% CI $0.85-0.94), p<0.0001$. A preliminary statistical study which data were not displayed did not show significant differences in permeability and MCCS neither between the cranial or caudal endplates nor between thoracic or lumbar vertebrae.

\section{Effective Permeability}

There was no statistical significant difference between flow in and flow out effective permeability in any of the groups studied. As a result, mean effective permeability of each specimen was used for further investigations (Table 2).

In control intervertebral units, effective permeability $\kappa_{0} / \mu$ was significantly greater in the center than in the periphery for both left and right specimens, $p=0.02$ and $p=0.03$, respectively. There was no significant difference between the left and right specimens.

In the instrumented vertebral units, the effective permeability was significantly lower on the tethered side than both in the center $(p=0.01)$ and the nontethered side $(p=0.04)$. There was no significant difference between the center and the nontethered side $(p>0.05)$. Effective permeability was significantly lower

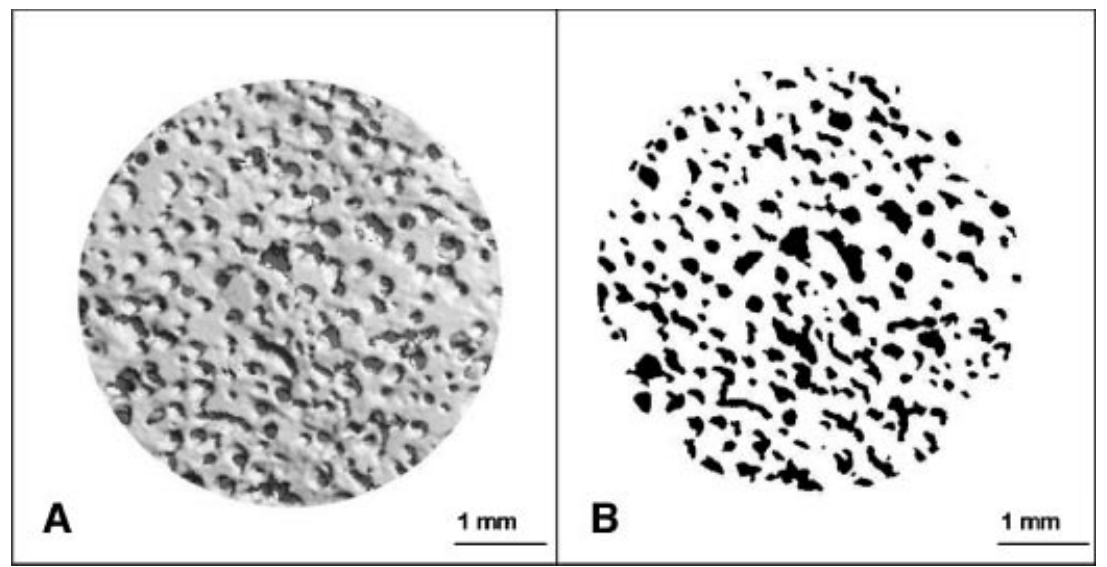

Figure 3. 2D image of the entire disc VEP interface in gray-scale mode (A) and after conversion into a binary $2 \mathrm{D}$ image $(\mathrm{B})$ where capillary buds in contact with the CEP are visualized in black. 
Table 2. Macroscopic Permeability and Marrow Contact Channel Surface in Control and Tethered Intervertebral Units According to the Location of the Samples

\begin{tabular}{|c|c|c|c|c|}
\hline Location & Control & Instrumented & $\Delta_{\text {rel }}(\%)$ & $p$ \\
\hline \multicolumn{5}{|c|}{ Flow-out permeability $\left(10^{-14} \mathrm{~m}^{4} / \mathrm{N} \mathrm{s}\right)$} \\
\hline Left lateral & $6.9 \pm 5.4$ & $3.7 \pm 2.7$ & -46.4 & 0.02 \\
\hline Central & $13.9 \pm 13.0$ & $6.8 \pm 7.1$ & -51.1 & 0.02 \\
\hline Right lateral & $9.6 \pm 8.9$ & $5.6 \pm 5.3$ & -41.7 & 0.19 \\
\hline \multicolumn{5}{|c|}{ Flow-in permeability $\left(10^{-14} \mathrm{~m}^{4} / \mathrm{N} \mathrm{s}\right)$} \\
\hline Left lateral & $6.1 \pm 2.5$ & $3.8 \pm 3.3$ & -37.7 & 0.001 \\
\hline Central & $14.5 \pm 18.2$ & $5.4 \pm 4.4$ & -62.7 & 0.08 \\
\hline Right lateral & $8.7 \pm 8.1$ & $7.4 \pm 11.2$ & -14.9 & 0.82 \\
\hline \multicolumn{5}{|c|}{ Mean permeability $\left(10^{-14} \mathrm{~m}^{4} / \mathrm{N} \mathrm{s}\right)$} \\
\hline Left lateral & $6.5 \pm 3.6$ & $3.8 \pm 2.8$ & -41.5 & 0.003 \\
\hline Central & $14.2 \pm 14.3$ & $6.1 \pm 5.0$ & -57.0 & 0.04 \\
\hline Right lateral & $9.1 \pm 8.2$ & $6.6 \pm 6.4$ & -27.5 & 0.38 \\
\hline \multicolumn{5}{|c|}{ Marrow contact channel surface (\%) } \\
\hline Left lateral & $20.4 \pm 7.9$ & $9.7 \pm 3.9$ & -52.5 & 0.005 \\
\hline Central & $33.9 \pm 11.4$ & $24.2 \pm 7.0$ & -28.6 & 0.04 \\
\hline Right lateral & $22.7 \pm 9.2$ & $19.3 \pm 8.3$ & -15.0 & 0.28 \\
\hline
\end{tabular}

$\Delta_{\text {rel }}$, relative difference; control unit versus tethered samples.

Numerical data are given as mean \pm standard deviation.

in the tethered vertebral units than in the controls $(p=0.004)$. The difference was particularly important in the center and on the tethered side, $-57 \%$ and $-41.5 \%$, respectively. The nontethered side showed a permeability decrease of $27.5 \%$.

\section{Marrow Contact Channel Surface (MCCS) of the Vascular Buds}

In the control vertebral units, MCCS was significantly higher in the center than in the periphery for both left and right specimens, $p=0.002$ and $p=0.009$, respectively. There was no significant difference between the left and right sides. The mean relative difference for MCCS between the center and the periphery was $31.4 \pm 17.4 \%$.

In the instrumented intervertebral units, MCCS was significantly lower on the tethered side than both in the center and on the nontethered side $(p<0.0001)$. There was no difference between the center and the nontethered side. In all specimens, MCCS was significantly lower in the instrumented intervertebral units than in the controls $(p=0.0009)$. The relative differences between instrumented and control levels were important in the center $(-28.6 \%)$ and on the tethered side $(-52.5 \%)$ and more limited on the nontethered side $(-15 \%)$.

\section{Correlations Between Effective Permeability and MCCS}

Correlations between effective permeability of the VEP and MCCS are plotted in Figure 4A for the control intervertebral units, and in Figure $4 \mathrm{~B}$ for the instrumented units. Pearson correlation coefficients are summarized in Table 3.

A significant correlation between effective permeability and MCCS was established since a coefficient $r^{2}$ of $0.43(p<0.0001)$. It also appeared that the correlation was stronger for instrumented units, $r^{2}=0.517$ $(p<0.0001)$ than for control units $r^{2}=0.288(p=0.07)$.

\section{DISCUSSION}

Solutes exchanges to and from the IVD occur through the VEP via passive diffusion but mostly by active convection. ${ }^{7,16,17}$ This nutrition route is precarious ${ }^{17,18}$ and is compromised in case of VEP disorders. ${ }^{8,19}$ Because they constrained the flow through the endplate, marrow contact channels are of prime influence on the energy loss by the fluid. In our study, we investigated the region of interest corresponding with the contact surface between the vascular network and the CEP. We initially hypothesized that effective permeability of the VEP was correlated to MCCS and influenced by

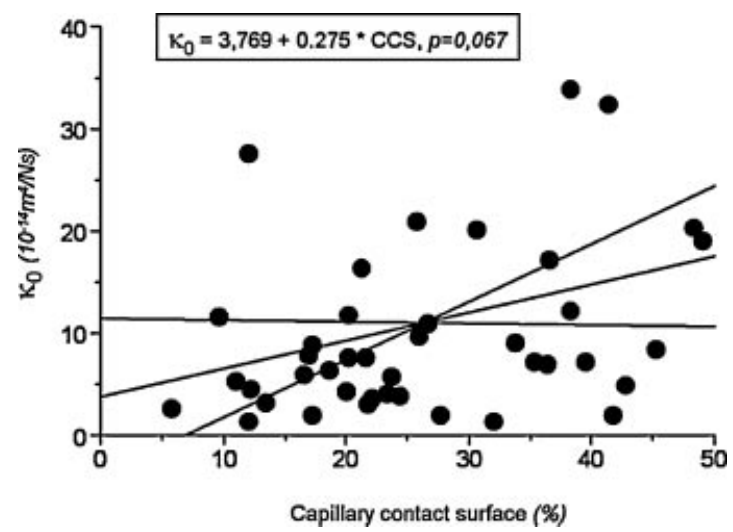

Figure 4. Correlation of the permeability of the VEP $k_{0}$ $\left(10^{-14} \mathrm{~m}^{4} / \mathrm{N} \mathrm{s}\right)$ with capillary contact surface $(\%)$ in control vertebral units (A) and instrumented units (B). Linear correlation and $95 \%$ confidence interval. 
Table 3. Correlations between Macroscopic

Permeability and Marrow Contact Channel Surfaces in Control and Tethered Intervertebral Units According to the Location of the Specimens

\begin{tabular}{lcl}
\hline & \multicolumn{2}{c}{ Surface } \\
\cline { 2 - 3 } Location & Control $\left(r^{2}\right)$ & Instrumented $\left(r^{2}\right)$ \\
\hline Flow-out permeability $\left(10^{-14} \mathrm{~m}^{4} / \mathrm{N} \mathrm{s}\right)$ & \\
All specimens & $0.329^{*}$ & $0.543^{* *}$ \\
Left lateral & $0.621^{*}$ & $0.450^{*}$ \\
Central & 0.103 & 0.418 \\
Right lateral & $0.531^{*}$ & $0.653^{* *}$ \\
Flow-in permeability $\left(10^{-14} \mathrm{~m}^{4} / \mathrm{N} \mathrm{s}\right)$ & \\
All specimens & 0.214 & $0.307^{*}$ \\
Left lateral & $0.667^{*}$ & 0.280 \\
Central & 0.118 & 0.504 \\
Right lateral & $0.549^{*}$ & 0.260 \\
Mean permeability $\left(10^{-14} \mathrm{~m}^{4} / \mathrm{N} \mathrm{s}\right)$ & \\
All specimens & 0.288 & $0.517^{* *}$ \\
Left lateral & $0.691^{*}$ & 0.374 \\
Central & 0.077 & $0.526^{*}$ \\
Right lateral & $0.558^{*}$ & $0.507^{*}$ \\
\hline
\end{tabular}

Correlations are expressed using Pearson or Spearman correlation coefficients.

${ }^{*} p<0.05 .{ }^{* *} p<0.01$.

pathological mechanical stimuli. To evaluate the reliability of our hypothesis, we implemented an experimental study in a growing porcine animal model subjected to an asymmetric vertebral tether in an intervertebral unit (vertebra-disc-vertebra). Court et al. ${ }^{20}$ subjected mice tail discs to static bending and found a $65 \%$ loss of cellularity and a significant increase in the apoptotic activity of the annulus on the concave side compared to the convex side. Similarly, Braun et al. ${ }^{21}$ in an experimental goat model of scoliosis, showed a decreased proteoglycan and hydroxyprolin content in the nucleus pulposus. Porcine models also showed a significant interest; ${ }^{22,23}$ in our study, we used skeletally immature pigs because for their high growth potential. ${ }^{24}$ The asymmetric tether induced an unbalanced growth associated with an asymmetrical compressive loading. ${ }^{25}$

Capillary buds were in contact with the CEP through the marrow contact channels of the subchondral bone. Gruber et al. ${ }^{2}$ analyzed the capillary network of VEP in a rat sand model only using a semi-quantitative scale with $44 \mu \mathrm{m}$ resolution micro-CT protocol. Benneker et al. ${ }^{5}$ limited the region of interest facing the nucleus pulposus and used a scanning electron microscopic technique. In our study, the emergence of marrow contact channels into the discal surface of the specimen was seen as a distribution pattern of openings, varying in density, size, and shape. Overall opening surface was quantified using a high-resolution micro-CT protocol. As the average diameter of the capillary was $100 \mu \mathrm{m}^{26}$ and that of the marrow contact channel was $50 \mu \mathrm{m}^{27}$ the $12 \mu \mathrm{m}$ resolution of the current study provided a significant reliability.

In the control group, MCCS was $35 \%$ in the center of VEP and $20 \%$ in the peripheral zone close from the annulus fibrosus $(p<0.05)$. Effective permeability was $30 \%$ greater in the center than in the periphery of the VEP. Our results were consistent with previous anatomic studies. ${ }^{6,7,9}$ Accadbled et al. ${ }^{8}$ showed in an ovine model that the center of the VEP was $28.5 \%$ more permeable than the periphery. This result was later confirmed in a swine model by Laffosse et al. ${ }^{28}$ with a significant difference up to $32 \%$. After chronic compression loading, we found a significant decrease of both MCCS (between 10\% and 50\%) and effective permeability (between $30 \%$ and 60\%) as compare to those of control units. Correlations between effective permeability and MCCS were maximal in left lateral specimens undergoing maximal compressive loading.

The consequences of mechanical stress on vertebral segment remodeling are complex. Modified mechanobiological factors due to segment deformation might modify the topology of capillary network and associated marrow contact channel in terms of porosity ratios and tortuosity knowing that these factors were of prime influence on transport properties in porous media. Concerning biochemical aspects, release of numerous pro inflammatory mediators ${ }^{29}$ by chondrocytes may also play a significant role. Among them, vascular endothelial growth factor (VGEF) is essential to the development of cartilage vascularization. ${ }^{30}$ However, this phenomenon could be counterbalanced by chondrocytes apoptosis induced by loading applied onto the CEP ${ }^{20,31}$ which would contribute to alter the epiphyseal vascular network of the VEP that is associated with disc degeneration. ${ }^{5}$ Other factors could interfere with vascular channels adjacent to the CEP. Turgut et al. ${ }^{12,13}$ reported in an adult rat degenerated discs model, the stimulatory effect of nimodipine, a calcium channel antagonist, and the negative effect of exogenous melatonin on the vascularization of the VEP. Iwahashi et al. ${ }^{11}$ demonstrated the negative effect of nicotine in a rabbit model and Moore et al. ${ }^{14}$ found increased vascularization adjacent to the CEP after experimental lesions of the annulus fibrosus in sheep potentially due to the angiogenic effects of inflammation in the healing process.

Although rarefaction of the capillary network seems to play a key role in the decrease in effective permeability of VEP, changes in the walls of the remaining vessels, subchondral bone sclerosis and initiation of CEP calcification may be amplifier factors. Better understanding of the consequences of mechanical stimuli on local vascularization and on the cascade of biochemical and biomolecular events should offer perspectives for research leading to a better knowledge of disc degeneration.

\section{ACKNOWLEDGMENTS}

The authors wish to thank Prof. Jean Puget for his technical support. Conflict of interest: No benefits in any form have been 
received or will be received by any authors from a commercial party related directly or indirectly to the subject of this article.

\section{REFERENCES}

1. Grunhagen T, Wilde G, Soukane DM, et al. 2006. Nutrient supply and intervertebral disc metabolism. J Bone Joint Surg Am 88:30-35.

2. Gruber HE, Ashraf N, Kilburn J, et al. 2005. Vertebral endplate architecture and vascularization: Application of micro-computerized tomography, a vascular tracer, and immunocytochemistry in analyses of disc degeneration in the aging sand rat. Spine 30:2593-2600.

3. Crock HV, Goldwasser M. 1984. Anatomic studies of the circulation in the region of the vertebral end-plate in adult Greyhound dogs. Spine 9:702-706.

4. Nachemson A, Lewin T, Maroudas A, Freeman MA. 1970. In vitro diffusion of dye through the end-plates and the annulus fibrosus of human lumbar inter-vertebral discs. Acta Orthop Scand 41:589-607.

5. Benneker LM, Heini PF, Alini M, et al. 2005. 2004 Young Investigator Award Junior: Vertebral endplate marrow contact channel occlusions and intervertebral disc degeneration. Spine 30:167-173.

6. Urban JP, Holm S, Maroudas A, Nachemson A. 1977. Nutrition of the intervertebral disk. An in vivo study of solute transport. Clin Orthop Relat Res 129:101-114.

7. Brodin H. 1955. Path of nutrition in articular cartilage and the intervertebral disk. Acta Orthop Scand 24:177-183.

8. Accadbled F, Laffosse JM, Ambard D, et al. 2008. Influence of location, fluid flow direction and tissue maturity on the macroscopic permeability of vertebral end plates. Spine 33: 612-619.

9. Oki S, Matsuda Y, Shibata T, et al. 1996. Morphologic differences of the vascular buds in the vertebral endplate: Scanning electron microscopy study. Spine 21:174-177.

10. Accadbled F, Ambard D, Sales de Gauzy J, Swider P. 2008. A measurement technique to evaluate the permeability distribution in the vertebral end-plate. Med Eng Phys 30:116-122.

11. Iwahashi M, Matsuzaki H, Tokuhashi Y, et al. 2002. Mechanism of intervertebral disc degeneration caused by nicotine in rabbits to explicate intervertebral disc disorders caused by smoking. Spine 27:1396-1401.

12. Turgut M, Uslu S, Uysal A, et al. 2003. Changes in vascularity of cartilage endplate of degenerated intervertebral discs in response to melatonin administration in rats. Neurosurg Rev 26:133-138.

13. Turgut M, Uysal A, Uslu S, et al. 2003. The effects of calcium channel antagonist nimodipine on end-plate vascularity of the degenerated intervertebral disc in rats. J Clin Neurosci 10: 219-223.

14. Moore RJ, Osti OL, Vernon-Roberts B, Fraser RD. 1992. Changes in endplate vascularity after an outer anulus tear in the sheep. Spine 17:874-878.

15. Laffosse JM, Odent T, Accadbled F, et al. 2010. Microcomputed tomography evaluation of vertebral end-plate trabecular bone changes in a porcine asymmetric vertebral tether. J Orthop Res 28:232-240.
16. Roberts S, Menage J, Urban JP. 1989. Biochemical and structural properties of the cartilage end-plate and its relation to the intervertebral disc. Spine 14:166-174.

17. Selard E, Shirazi-Adl A, Urban JPG. 2003. Finite element study of nutrient diffusion in the human intervertebral disc. Spine 28:1945-1953.

18. Urban MR, Fairbank JC, Etherington PJ, et al. 2001. Electrochemical measurement of transport into scoliotic intervertebral discs in vivo using nitrous oxide as a tracer. Spine 26:984-990.

19. Donisch EW, Trapp W. 1971. The cartilage endplates of the human vertebral column (Some considerations of postnatal development). Anat Rec 169:705-716.

20. Court C, Chin JR, Liebenberg E, et al. 2007. Biological and mechanical consequences of transient intervertebral disc bending. Eur Spine J 16:1899-1906.

21. Braun JT, Ogilvie JW, Akyuz E, et al. 2003. Experimental scoliosis in an immature goat model: A method that creates idiopathic-type deformity with minimal violation of the spinal elements along the curve. Spine 28:2198-2203.

22. Smit TH. 2002. The use of a quadruped as an in vivo model for the study of the spine-Biomechanical considerations. Eur Spine J 11:137-144.

23. Kettler A, Liakos L, Haegele B, Wilke HJ. 2007. Are the spines of calf, pig and sheep suitable models for pre-clinical implant tests? Eur Spine J 16:2186-2192.

24. Odent Th, Cachon Th, Peultier B, et al. Porcine scoliosis model based on animal growth created with minimal invasive off-set tethering. 43rd Annual Meeting Scoliosis Research Society, Salt Lake City, Utah, USA, September 1013, 2008.

25. Bylski-Austrow DI, Wall EJ, Rupert MP, et al. 2001. Growth plate forces in the adolescent human knee: A radiographic and mechanical study of epiphyseal staples. J Pediatr Orthop 21:817-823.

26. Oki S, Matsuda Y, Itoh T, et al. 1994. Scanning electron microscopic observations of the vascular structure of vertebral end-plates in rabbits. J Orthop Res 12:447449 .

27. Benneker LM, Heini PF, Anderson SE, et al. 2005. Correlation of radiographic and MRI parameters to morphological and biochemical assessment of intervertebral disc degeneration. Eur Spine J 14:27-35.

28. Laffosse JM, Accadbled F, Odent T, et al. 2009. Influence of asymmetric tether on the macroscopic permeability of the vertebral end plate. Eur Spine J 18:1971-1977.

29. Loeser RF. 2006. Molecular mechanisms of cartilage destruction: Mechanics, inflammatory mediators, and aging collide. Arthritis Rheum 54:1357-1360.

30. Maes C, Stockmans I, Moermans K, et al. 2004. Soluble VEGF isoforms are essential for establishing epiphyseal vascularization and regulating chondrocyte development and survival. J Clin Invest 113:188-199.

31. Ariga K, Yonenobu K, Nakase T, et al. 2003. Mechanical stress-induced apoptosis of endplate chondrocytes in organcultured mouse intervertebral discs: An ex vivo study. Spine 28:1528-1533. 